\title{
Characteristics of Synchronous and Metachronous Multiple Gastric Tumors after Endoscopic Submucosal Dissection of Early Gastric Neoplasm
}

\author{
Hyun Jik Lee ${ }^{1}$, Yoo Jin Lee', Ju Yup Lee', Eun Soo Kim², Woo Jin Chung ${ }^{1}$, Byoung Kuk Jang', Kyung Sik Park', Jae Seok Hwang ${ }^{1}$ \\ and Kwang Bum Cho ${ }^{1}$
}

Department of Internal Medicine, ${ }^{1}$ Keimyung University School of Medicine, Daegu, ${ }^{2}$ Kyungpook National University School of Medicine, Daegu, Korea

Background/Aims: Endoscopic submucosal dissection (ESD) has been widely accepted as a method of treatment of early gastric tumor. This study aimed to identify the incidence and characteristics of multiple gastric tumors after ESD.

Methods: Patients with early gastric tumors who were treated by ESD from January 2004 to June 2012 and followed up with endoscopic examination periodically for at least 1 year were enrolled. All multiple gastric lesions were subsequently treated with ESD and the medical records of the patients were retrospectively reviewed.

Results: In total, 643 patients were included. The mean duration of endoscopic follow-up was $45.27 \pm 27.59$ (range, 12-148) months. Overall, 144 patients (22.4\%) showed multiple gastric tumors during the follow-up period (44 synchronous [6.8\%] and 100 metachronous [15.5\%]). The cumulative incidence rate steadily increased during the follow-up period. More than $50 \%$ of the tumors that developed at the same longitudinal location of the stomach were of the same macroscopic and histological type as the primary lesions.

Conclusions: Because synchronous and/or metachronous gastric tumors are common, considerable attention should be paid to detect multiple gastric lesions after ESD of early gastric neoplasm. Clin Endosc 2018;51:266-273

Key Words: Stomach neoplasms; Endoscopic submucosal dissection; Neoplasms, second primary

\section{INTRODUCTION}

Early gastric cancer (EGC) is defined as a neoplasm confined to the mucosa or submucosa regardless of the presence of regional lymph node metastasis. ${ }^{1,2}$ Gastric dysplasia is defined as benign unequivocal neoplastic epithelial lesion without histologic evidence of invasive carcinoma and reparative changes. ${ }^{3}$ Currently, the diagnostic rate of EGC and gastric

Received: July 6, 2017 Revised: August 10, 2017

Accepted: September 17, 2017

Correspondence: Kwang Bum Cho

Division of Gastroenterology and Hepatology, Department of Internal Medicine, Keimyung University School of Medicine, 56 Dalseong-ro, Jung-gu, Daegu 41931, Korea

Tel: +82-53-250-8096, Fax: +82-53-250-7434, E-mail: chokb@dsmc.or.kr ORCID: https://orcid.org/0000-0003-2203-102X

(c) This is an Open Access article distributed under the terms of the Creative Commons Attribution Non-Commercial License (http://creativecommons.org/ licenses/by-nc/3.0) which permits unrestricted non-commercial use, distribution, and reproduction in any medium, provided the original work is properly cited. dysplasia has increased owing to improved diagnostic procedures and nationwide surveillance programs. The incidence of gastric dysplasia has been reported between $9 \%$ and $20 \%$ in high-risk areas for gastric cancers. ${ }^{4}$

Endoscopic resection has been widely accepted as the standard treatment for EGC without the risk of regional lymph node metastasis, because it has the advantages of being less invasive, and comparable with surgery. ${ }^{5-7}$ Many studies have demonstrated that gastric dysplasia can also be treated by endoscopic resection because it has a risk of malignancy and should be regarded as a precursor of gastric cancer. ${ }^{8}$ Among several methods of endoscopic resection, endoscopic submucosal dissection (ESD) has advantages over endoscopic mucosal resection for treating early gastric neoplasm consisting of EGC and gastric dysplasia, in that it allows en bloc resection and has an expanding range of indications. ${ }^{9-11}$

Consequently, the number of medical facilities that perform gastric tumor ESD has increased, and multiple gastric tumors 
after ESD have become an emerging concern owing to the widespread acceptance of ESD. However, the majority of published literature to date has reported on synchronous lesions after gastrectomy or endoscopic resection of EGC. ${ }^{12-14}$ Data on metachronous lesions after ESD for early gastric neoplasms are still limited, and the long-term results of the incidence of metachronous tumor after ESD have not been fully evaluated. Therefore, we performed a retrospective analysis of the incidence and characteristics of synchronous and metachronous multiple gastric tumors after ESD of early gastric neoplasm over a long-term follow-up.

\section{MATERIALS AND METHODS}

\section{Patients}

ESD was performed in 1,390 patients at Keimyung University Dongsan Hospital in Daegu, Korea, for the treatment of early gastric neoplasm between June 2004 and June 2012. All patients were recommended to undergo endoscopy at 3 , 6 , and 12 months after the procedure, and yearly follow-up thereafter. If patients had multiple lesions at the time of ESD, only the main lesions were included in the analysis. The main lesion was defined as the most malignant or dysplastic lesion. ${ }^{12}$ If multiple lesions had the same histology, the largest lesion was regarded as the main lesion. Longitudinal tumor locations were classified as being in the upper (cardia, fundus, and upper body), middle (mid body, lower body, and angle), and lower (antrum and prepylorus) parts of the stomach. ${ }^{15}$ Circumferential tumor locations were defined as anterior wall, posterior wall, lesser curvature, and greater curvature. ${ }^{12}$ The maximum tumor diameter in the gastric neoplasm was macroscopically estimated. The endoscopic gross morphology of the tumors was classified based on the Paris classification. ${ }^{16}$ The presence of atrophy was reviewed endoscopically by an expert endoscopist, and intestinal metaplasia was histologically assessed based on the resected specimen. The study was approved by the ethics committee (Review board of Keimyung University Dongsan Hospital (No. 13-272). Written informed consent was obtained from all patients.

\section{Definitions}

We classified multiple gastric tumors based on the time at which the lesions were detected. ${ }^{17}$ Multiple gastric tumors detected within 1 year of initial ESD were classified as synchronous lesion. Metachronous lesion was defined as a new gastric tumor in the area other than the site of primary lesion and diagnosed after 1 year of the initial ESD. We simply reclassified endoscopic gross types of gastric tumors into three groups: polypoid (type 0-I), flat elevated (type 0-IIa, 0-IIb, and $0-\mathrm{IIa}+\mathrm{IIc}$ ), and superficial depressed (type 0-IIc, 0-III, and $0-\mathrm{IIc}+\mathrm{IIa}$ ). Helicobacter pylori status was considered to be positive if the result of histology, rapid urease test, or urea breath test was positive.

\section{Endoscopic submucosal dissection methods}

Standardized ESD procedure was performed in patients under conscious sedation by three experts, each of whom had performed ESD more than 100 times for more than 2 years before the procedure. Several spots were marked with needle knife or argon plasma coagulation 5 to $10 \mathrm{~mm}$ outside the margin of the lesion. Subsequently, hypertonic saline mixed with epinephrine $(1: 10,000)$ was injected into the submucosa to lift the lesion. The IT knife or hook knife was inserted into the initial incision, and electrosurgical current was applied using an electrosurgical generator. All patients fasted after the procedure along with the use of a proton pump inhibitor. Endoscopy was performed within 3 days to confirm the periprocedural bleeding.

\section{Evaluation of clinicopathologic feature}

The resected specimens were stretched, pinned to a polystyrene plate, and embedded in $8 \%$ formaldehyde for $24 \mathrm{~h}$ for fixation. The fixed specimen was sectioned before histological processing, and staining with hematoxylin and eosin. All resected specimens were evaluated by histopathologic examination based on the Vienna classification. ${ }^{18}$ The final pathologic diagnoses were classified as dysplasia and gastric cancer with differentiated or undifferentiated type, according to the Japanese classification. ${ }^{19}$

\section{Statistical analysis}

Data were analyzed using the Fisher's exact or Chi-square tests. To compare continuous variables among groups, ANOVA test was performed, as appropriate. The follow-up period was calculated from the date of the initial ESD to the detection date of the first synchronous and metachronous multiple gastric tumors or the date of the last endoscopic examination for patients in whom multiple lesions were not diagnosed. The cumulative incidence rate of synchronous or metachronous tumors was plotted using the Kaplan-Meier method. All data analyses were performed using SPSS version 22.0 (SPSS Inc., Chicago, IL, USA). $P$-values $<0.05$ were considered statistically significant.

\section{RESULTS}

\section{Baseline patient and lesion characteristics}

We retrospectively reviewed the prospectively collected ESD database system. Endoscopic resection was performed in 1,390 
patients, and we excluded 362 patients whose histopathologic result was piecemeal, margin positive, or undetermined. We excluded 125 patients who underwent subsequent surgical resection owing to non-curative resection, 234 patients who

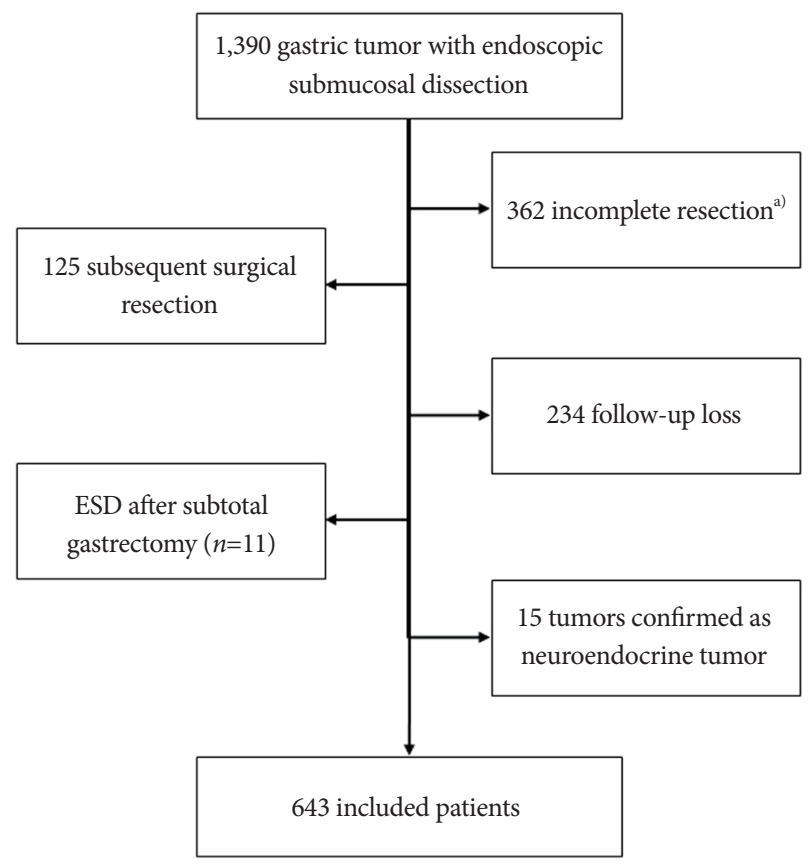

Fig. 1. Flow chart of included patients. ESD, endoscopic submucosal dissection. ${ }^{\text {al) }}$ Piecemeal, margin-positive, or undetermined. were lost to follow-up within 1 year, and 11 patients who underwent prior gastrectomy before ESD. Fifteen patients who had carcinoid tumor after ESD also dropped out of the study. Finally, 643 patients (499 with a solitary lesion and 144 with two or more synchronous or metachronous lesions; 355 EGC and 288 adenomas) who underwent ESD for early gastric neoplasm met the inclusion criteria for this study (Fig. 1).

\section{Incidences and characteristics of synchronous and metachronous lesion}

Consecutive 643 patients were included in this study. The mean period of endoscopy follow-up was $45.27 \pm 27.59$ (range, $12-148)$ months. Overall, 144 patients (22.4\%) showed multiple gastric tumors during the follow-up period. Among them, $44(6.8 \%)$ synchronous lesions were detected within 1 year of the initial ESD. Thirteen synchronous lesions were already found at the time of endoscopic resection, and 31 were detected within 1 year of endoscopic resection. Of these patients, 22 subsequently developed metachronous tumors during the follow-up period, and they were classified as the metachronous lesion subgroup in our study. Finally, metachronous lesions had developed in 100 (15.5\%) patients. Of 144 multiple gastric tumors, 43 (29.9\%) were differentiated type-cancers, 8 (5.6\%) were undifferentiated-type cancers, and 93 (64.6\%) were adenomas. Of these patients, nine subsequently developed third multiple gastric tumors.

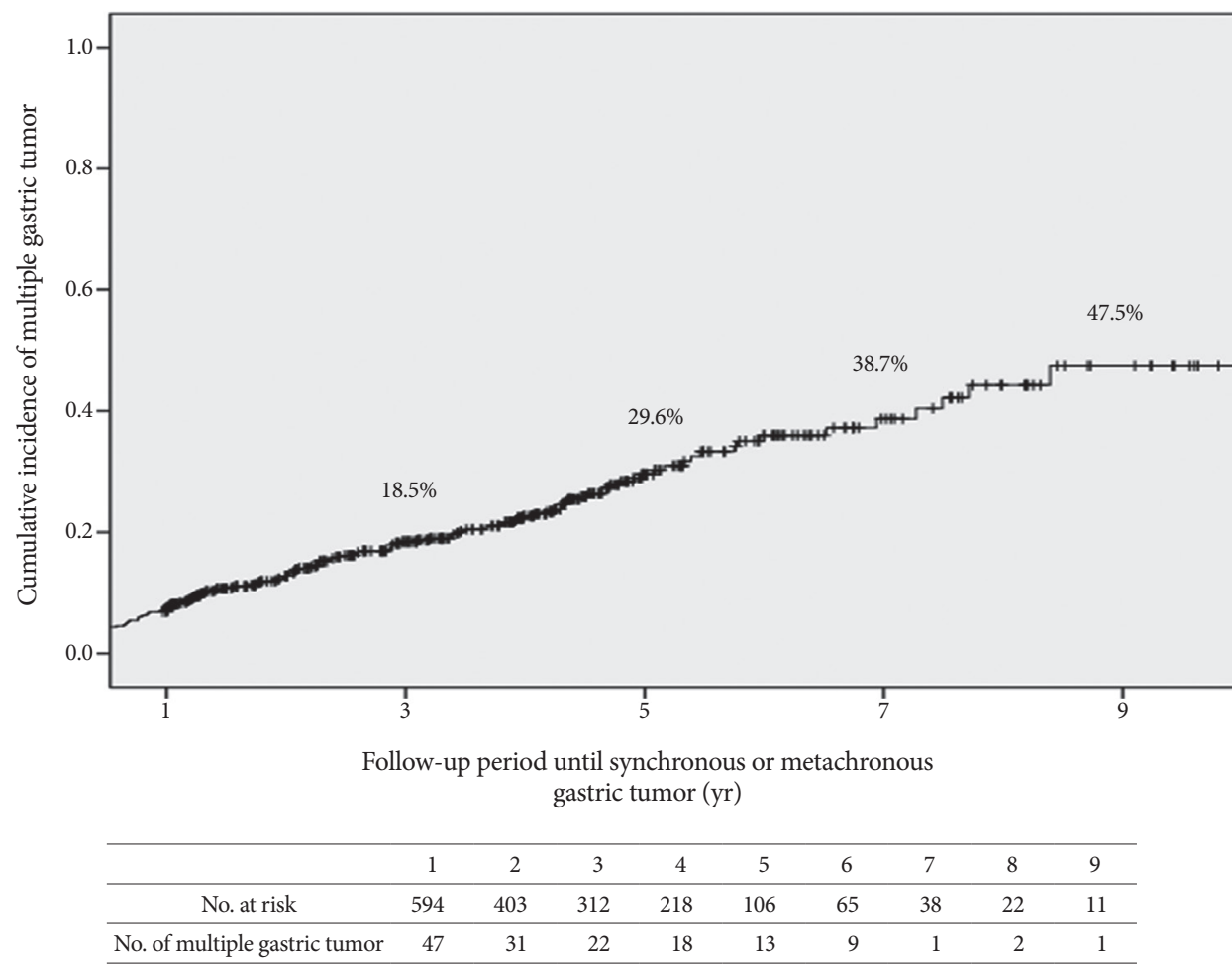

Fig. 2. Cumulative incidence curve of synchronous and metachronous gastric tumor after endoscopic submucosal dissection of early gastric neoplasm. 


\section{Cumulative incidences of synchronous and meta- chronous lesion}

The cumulative incidence curve of multiple synchronous and metachronous tumors showed a linear increase. The cumulative incidence rates at 3,5,7, and 9 years were $18.5 \%$, $29.6 \%, 38.7 \%$, and $47.5 \%$, respectively (Fig. 2 ).

Fig. 3 shows the Kaplan-Meier plots for multiple gastric tu- mors based on the histologic differences of the primary lesion. The cumulative incidence showed no significant difference between the dysplasia and cancer groups ( $p=0.525$ ). The cumulative incidence curve of synchronous and metachronous tumors between patients older than 60 years and those younger than 60 years is plotted in Fig. 4 ( $p=0.072$ ).

The mean time interval from the initial ESD procedure to

Table 1. Characteristics of Patients with Gastric Mucosal Neoplasm and Their Initial Lesions

\begin{tabular}{|c|c|c|c|c|}
\hline Factors $(n)$ & $\begin{array}{l}\text { Solitary } \\
(n=499)\end{array}$ & $\begin{array}{c}\text { Synchronous }^{\mathrm{a})} \\
(n=44)\end{array}$ & $\begin{array}{l}\text { Metachronous } \\
\quad(n=100)\end{array}$ & $p$-value \\
\hline Age at diagnosis, mean \pm SD & $65.3 \pm 9.1$ & $69.6 \pm 8.6$ & $66.0 \pm 8.5$ & 0.009 \\
\hline Sex $(M: F)$ & $1: 0.5$ & $1: 0.2$ & $1: 0.5$ & 0.108 \\
\hline Location (long axis) & & & & 0.676 \\
\hline Upper & $28(5.6 \%)$ & $3(6.8 \%)$ & $5(5.6 \%)$ & \\
\hline Middle & $154(30.9 \%)$ & $18(40.9 \%)$ & $33(33.0 \%)$ & \\
\hline Lower & $317(63.5 \%)$ & $23(52.3 \%)$ & $62(62.0 \%)$ & \\
\hline Location (short axis) & & & & 0.660 \\
\hline Anterior wall & $116(23.2 \%)$ & $7(15.9 \%)$ & $21(21.0 \%)$ & \\
\hline Lesser curvature & $188(37.7 \%)$ & $15(34.1 \%)$ & $34(34.0 \%)$ & \\
\hline Posterior wall & $106(21.2 \%)$ & $12(27.3 \%)$ & $21(21.0 \%)$ & \\
\hline Greater curvature & $89(17.8 \%)$ & $10(22.7 \%)$ & $24(24.0 \%)$ & \\
\hline Tumor size $(\mathrm{mm}$, mean $\pm \mathrm{SD})$ & $14.8 \pm 11.1$ & $16.9 \pm 12.2$ & $14.8 \pm 11.8$ & 0.250 \\
\hline Tumor size $\geq 20 \mathrm{~mm}$ & $125(25.1 \%)$ & $11(25.0 \%)$ & $23(23.0 \%)$ & 0.891 \\
\hline Gross type & & & & 0.105 \\
\hline Polypoid & $34(6.8 \%)$ & $4(9.1 \%)$ & $2(2.0 \%)$ & \\
\hline Flat elevated & $360(72.1 \%)$ & $36(81.8 \%)$ & $79(79.0 \%)$ & \\
\hline Depressed or ulcer & $105(21.0 \%)$ & $4(9.1 \%)$ & $19(19.0 \%)$ & \\
\hline Histology & & & & 0.557 \\
\hline Differentiated cancer & $267(50.5 \%)$ & $28(60.9 \%)$ & $36(45.0 \%)$ & \\
\hline Undifferentiated cancer & $26(4.9 \%)$ & $2(4.3 \%)$ & $4(5.0 \%)$ & \\
\hline Dysplasia & $236(44.6 \%)$ & $16(34.8 \%)$ & $40(50.0 \%)$ & \\
\hline Multiple lesions at initial ESD & $97(19.4 \%)$ & $13(29.5 \%)$ & $21(21.0 \%)$ & 0.276 \\
\hline Depth of invasion & & & & 0.348 \\
\hline Mucosa & $468(93.8 \%)$ & $39(88.6 \%)$ & $95(95.0 \%)$ & \\
\hline Submucosa & $31(6.2 \%)$ & $5(11.4 \%)$ & $5(5.0 \%)$ & \\
\hline \multicolumn{5}{|l|}{ Comorbidities } \\
\hline Hypertension & $183(36.7 \%)$ & $19(43.2 \%)$ & $29(29.0 \%)$ & 0.203 \\
\hline Diabetes mellitus & $83(16.6 \%)$ & $5(11.4 \%)$ & $15(15.0 \%)$ & 0.620 \\
\hline Cardiovascular disease & $27(5.4 \%)$ & $4(9.1 \%)$ & $10(10.0 \%)$ & 0.181 \\
\hline Cerebrovascular disease & $25(5.0 \%)$ & $3(6.8 \%)$ & $2(2.0 \%)$ & 0.361 \\
\hline Liver cirrhosis & $7(1.4 \%)$ & $1(2.3 \%)$ & $1(1.4 \%)$ & 0.668 \\
\hline Chronic kidney disease & $10(2.0 \%)$ & 0 & $1(1.0 \%)$ & 0.864 \\
\hline
\end{tabular}

$\mathrm{SD}$, standard deviation; ESD, endoscopic submucosal dissection.

${ }^{\text {a) }}$ Twenty two patients had both synchronous and metachronous lesions. In this analysis, they are grouped with the metachronous lesion subgroup. 


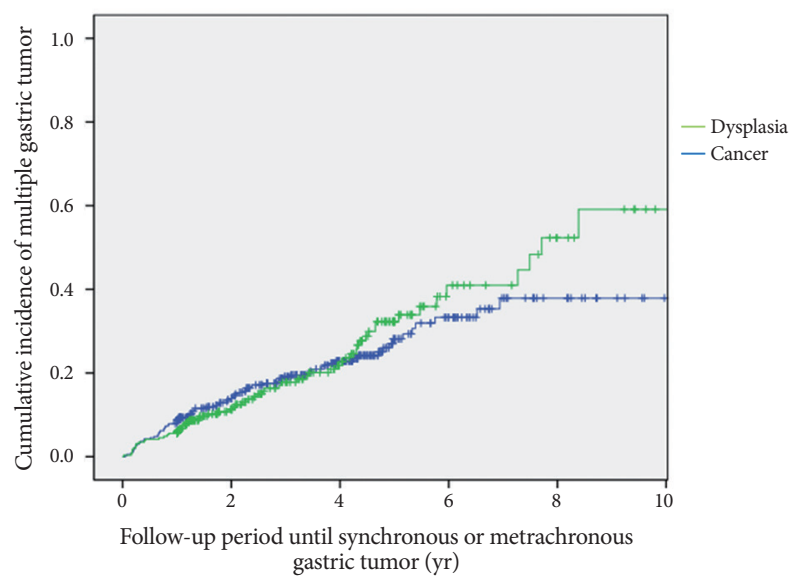

Fig. 3. Kaplan-Meier analysis of the incidence rate of multiple gastric tumors in patients according to histologic differentiation of the primary lesion $(p=0.525)$.

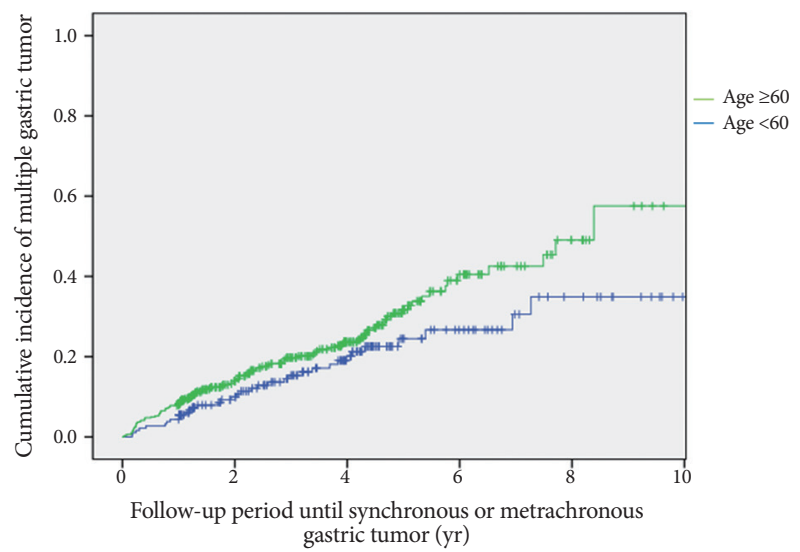

Fig. 4. Kaplan-Meier analysis of the incidence rate of multiple gastric tumors in patients by age at diagnosis $(p=0.072)$.

the diagnosis of secondary multiple neoplasms was approximately 5.1 (range, 1-10.3) months and 38.2 (range, 12-124.6) months in synchronous and metachronous tumors, respectively.

\section{Comparison of clinicopathologic characteristics of the patients and initial lesions between solitary and multiple lesion groups}

Table 1 shows the patient and lesion characteristics with early gastric neoplasm and their initial lesions. The male-tofemale patient ratio was approximately 2:1 (428 men and 215 women). The mean age at diagnosis of the synchronous lesion was the highest among the three groups, and it decreased stepwise in the order of metachronous and solitary groups (69.6 $\pm 8.6,66.0 \pm 8.5$ and $65.3 \pm 9.1$ years, respectively, $p=0.009$ ). The mean lesion size of the synchronous group was $16.9 \pm 12.2$ $\mathrm{mm}$ and larger than the lesion size in other groups; however, the difference in lesion size among the groups was not statistically significant. The characteristics of the initially resected lesions, including location, number, gross type, histological type, and invasion depth had no significant association with the development of secondary multiple tumors. In addition, no significant differences were found in patient comorbidities among the three groups.

\section{Clinicopathological similarities of multiple gastric tumors}

The clinicopathologic features of the 144 lesions with synchronous or metachronous gastric tumor are shown in Table 2. More than $50 \%$ of the multiple tumors were revealed to have the same gross type as the primary lesion had and to be located in the same longitudinal location of the stomach (67.4\% and $54.2 \%$, respectively). Irrespective of the macroscopic type of the primary tumor, the most common type of multiple gastric tumors is the flat elevated type (72.9\%). More than 50\% of multiple gastric tumors were discovered to be of the same histologic type as the primary tumor (54.2\%).

\section{DISCUSSION}

ESD is accepted as a standard treatment for early gastric neoplasm; but the incidence of metachronous tumor after ESD was higher than that after gastrectomy, because ESD preserves most of the stomach. ${ }^{20,21}$ The incidence of metachronous cancer after endoscopic resection has been reported to range from $5.1 \%$ to $14 \% .{ }^{6,22-24}$ In this study, patients with metachronous gastric tumor accounted for $15.5 \%$ of the total patients, which was similar to previous reports, but was relatively high. The cumulative incidence of multiple gastric tumors increased constantly after ESD in our study. This result can be extrapolated by the large proportion of patients with dysplasia (44.8\%) in our study. We speculated that gastric dysplasia should be included because it is considered to be a direct precursor of gastric adenocarcinoma, and a recently reported guideline has also recommended complete removal of gastric dysplasia when it is safe to do so. ${ }^{25}$ This difference may be caused by the strict inclusion criteria in the present study. We included subjects histologically confirmed to have undergone complete curative resection and excluded those who had undergone subsequent surgical resection. As a result, very small proportion of patients with undifferentiated or submucosal invasive cancer was included in our study (Table 1). We attempted to distinguish synchronous or metachronous lesions from local recurrence and increased the reliability of our results.

Among the 643 patients analyzed in this study, the rate of synchronous multiple lesions was $6.8 \%$ (44/643), which was slightly lower than that reported in other studies (9\%$14 \%) .^{12,26-28}$ This may be related to 22 patients who had both 
Table 2. Clinicopathological Similarities of Multiple Gastric Tumors

\begin{tabular}{|c|c|c|c|}
\hline Primary $\rightarrow$ secondary & $\begin{array}{c}\text { Synchronous } \\
\text { (44 lesions) }\end{array}$ & $\begin{array}{c}\text { Metachronous } \\
\text { (100 lesions) }\end{array}$ & $\begin{array}{c}\text { Total } \\
\text { (144 lesions) }\end{array}$ \\
\hline \multicolumn{4}{|l|}{ Gross type } \\
\hline Polypoid $\rightarrow$ polypoid/flat elevated/depressed & $0 / 2 / 2$ & $0 / 2 / 0$ & $0 / 4 / 2$ \\
\hline Flat elevated $\rightarrow$ polypoid/flat elevated/depressed & $4 / 28 / 4$ & $7 / 60 / 12$ & $11 / 88 / 16$ \\
\hline Depressed $\rightarrow$ polypoid/flat elevated/depressed & $0 / 4 / 0$ & $1 / 9 / 9$ & $1 / 13 / 9$ \\
\hline Same gross type & $28(63.6 \%)$ & $69(69.0 \%)$ & $97(67.4 \%)$ \\
\hline \multicolumn{4}{|l|}{ Location (long axis) } \\
\hline Upper $\rightarrow$ upper/mid/lower & $1 / 1 / 1$ & $1 / 3 / 1$ & $2 / 4 / 2$ \\
\hline Mid $\rightarrow$ upper/mid/lower & $4 / 8 / 6$ & $3 / 15 / 15$ & $7 / 23 / 21$ \\
\hline Lower $\rightarrow$ upper/mid/lower & $2 / 8 / 13$ & $3 / 19 / 40$ & $5 / 27 / 53$ \\
\hline Same location & $22(50.0 \%)$ & $56(56.0)$ & $78(54.2 \%)$ \\
\hline \multicolumn{4}{|l|}{ Location (short axis) } \\
\hline $\mathrm{AW} \rightarrow \mathrm{AW} / \mathrm{LC} / \mathrm{PW} / \mathrm{GC}$ & $0 / 1 / 6 / 0$ & $5 / 6 / 5 / 5$ & $5 / 7 / 11 / 5$ \\
\hline $\mathrm{LC} \rightarrow \mathrm{AW} / \mathrm{LC} / \mathrm{PW} / \mathrm{GC}$ & $5 / 6 / 1 / 3$ & $8 / 12 / 10 / 4$ & $13 / 18 / 11 / 7$ \\
\hline $\mathrm{PW} \rightarrow \mathrm{AW} / \mathrm{LC} / \mathrm{PW} / \mathrm{GC}$ & $2 / 5 / 4 / 1$ & $3 / 8 / 5 / 5$ & $5 / 13 / 9 / 6$ \\
\hline $\mathrm{GC} \rightarrow \mathrm{AW} / \mathrm{LC} / \mathrm{PW} / \mathrm{GC}$ & $5 / 1 / 2 / 2$ & $3 / 3 / 7 / 11$ & $8 / 4 / 9 / 13$ \\
\hline Same location & $12(27.3 \%)$ & $33(33.0 \%)$ & $45(31.3 \%)$ \\
\hline \multicolumn{4}{|l|}{ Histologic type } \\
\hline Cancer $\rightarrow$ cancer/dysplasia & $10 / 18$ & $23 / 30$ & $33 / 48$ \\
\hline Dysplasia $\rightarrow$ cancer/dysplasia & $4 / 12$ & $14 / 33$ & $18 / 45$ \\
\hline Same histologic type & $22(50.0 \%)$ & $56(56.0 \%)$ & $78(54.2 \%)$ \\
\hline
\end{tabular}

AW, anterior wall; LC, lesser curvature; PW, posterior wall; GC, greater curvature.

synchronous and metachronous lesions that were grouped with the metachronous lesion subgroup in our study. As a result, the real incidence of synchronous lesions after ESD may be higher than the $6.8 \%$ calculated in the present study. Therefore, it would be more accurate to state that the lowest incidence of synchronous neoplasm is $7.0 \%$.

The cumulative incidence rate steadily increased during the follow-up period. At 5 years after ESD, multiple gastric tumors developed in approximately $30 \%$ of ESD cases in early gastric neoplasm. These findings imply that synchronous and metachronous lesions are not rare, because the recent progress in endoscopic examination has resulted in increased detection of multiple gastric tumors. In clinical practice, the follow-up frequency of each patient varies widely, because frequent endoscopic follow-up limits the quality of life of the patients and increases the overall medical cost. ${ }^{6}$ The appropriate time limit for surveillance of multiple gastric tumors is unclear, because only few studies on metachronous tumors were assessed more than 10 years after endoscopic resection. ${ }^{6,29}$ Scheduled endoscopic surveillance is necessary and might help detect multiple gastric tumors, but no standardized consensus for endoscopic surveillance period and interval for secondary gastric tumors after ESD exists. ${ }^{30,31}$ Therefore, identification of high-risk patients is important for determining a schedule of endoscopic surveillance after ESD. Previous studies suggested that old age is a significant risk factor for multiple gastric neoplasms. ${ }^{22,32}$ Similarly, the cumulative incidence was higher in elderly patients aged more than 60 years in the present study $(p=0.072)$. The reason for old age being associated with metachronous tumor is unclear; it may be attributed to the multistep model of gastric carcinogenesis. Cahill et al. suggested a trend toward increased cell replication from normal mucosa to atrophic gastritis, to intestinal metaplasia to carcinoma. ${ }^{33}$ In older individuals, the gastric glands are generally atrophic with the increase of intestinal metaplasia. Thus, the majority of gastric cancers that develop in elderly patients are a background of intestinal metaplasia, and these cancers are frequently associated with subsequent multiple gastric lesions. ${ }^{34}$

H. pylori infection has been regarded as one of the important causes of gastric cancer. ${ }^{35}$ In this study, data for $H$. pylori infection status was missing in 210 patients and 433 patients with any of the $H$. pylori tests results were included. 
H. pylori infection was identified in 189 (56.6\%), 16 (53.3\%) and $41(59.4 \%)$ patients in the solitary, synchronous and metachronous groups, respectively. Among 246 patients with H. pylori-positive results, 138 patients (56.1\%) underwent eradication therapy. The metachronous gastric neoplasms occurred more frequently in $\mathrm{H}$. pylori-infected patients, which is similar to other reports, ${ }^{36,37}$ however no significant difference $(p=0.750)$ was found between the groups. The period of $H$. pylori infection is possibly presumed to be closely related with the occurrence of atrophic gastritis, intestinal metaplasia, and subsequent gastric neoplasms. Considering the multistep processes that started from chronic inflammation of the gastric mucosa, which slowly progresses to atrophic gastritis, intestinal metaplasia, and dysplasia to gastric adenocarcinomas, ${ }^{38} \mathrm{H}$. pylori uninfected status may inhibit the growth rate of metachronous gastric neoplasms. ${ }^{35} \mathrm{~A}$ recently reported prospective, randomized study also suggested that $H$. pylori eradication might delay the growth of metachronous cancer. ${ }^{39}$ Although several studies have reported that $H$. pylori eradication can reduce the multifocal development of metachronous lesions, the effect of eradication after endoscopic resection for gastric neoplasms remains debatable. ${ }^{37,39-41}$ In our study, $H$. pylori infection status were small in number and few patients underwent urea breath test or histologic evaluation to confirm successful eradication; thus, we cannot analyze the effect of eradication of $H$. pylori on the development of secondary multiple neoplasms after ESD. Larger studies are required to clarify this issue.

More than 50\% of the neoplasms in the 144 patients with multiple gastric lesions during the follow-up period developed at the same longitudinal location of the stomach, and showed the same gross type and histopathological type as that shown by the primary lesions $(54.2 \%, 67.4 \%$, and $54.2 \%$, respectively). A few studies have suggested that the histologic type of tumor and tumor number are important risk factors for multiple gastric neoplasms. ${ }^{12,36}$ In our study, these factors had no significant relationship with metachronous occurrence, and the cumulative incidence of multiple gastric tumors based on primary histologic difference did not show a significant difference (Fig. 3). In addition, there was no significant difference in the incidence of synchronous gastric cancer and dysplasia according to the histologic type of the primary tumor $(2.8 \%$, $5.1 \%$ in primary cancer group vs. $1.4 \%, 4.2 \%$ in primary dysplasia group, $p=0.356)$, and metachronous gastric cancer and dysplasia (6.5\%, $8.5 \%$ in primary cancer group vs. $4.9 \%, 11.5 \%$ in primary dysplasia group, $p=0.372$ ). Most multiple secondary tumors were detected as superficial lesions that imply that these lesions can be removed by subsequent ESD without surgical resection $(n=108,75 \%)$. Therefore, the endoscopist should keep these characteristics in mind, and conduct care- ful follow-ups to facilitate early detection of multiple gastric lesions regardless of the primary histology of the lesions.

Our study had several limitations. First, potential information biases might have occurred owing to the retrospective design of this study. Second, we did not evaluate the severity and extension of intestinal metaplasia and atrophic gastritis, because the grading system of atrophic gastritis and intestinal metaplasia is not well defined owing to their lack of standardization. Third, the data regarding $H$. pylori infection status were small in number, and the duration of $H$. pylori infection was uncertain.

In conclusion, as synchronous and/or metachronous gastric tumors are common after ESD of early gastric neoplasm, substantial attention should be paid to detect multiple gastric tumors. The early detection and treatment of multiple gastric tumors after ESD require strict long-term post-procedural surveillance, particularly in elderly patients. Prospective studies on risk factors for multiple gastric tumors and adequate surveillance schedule after ESD of gastric tumors are warranted.

\section{Conflicts of Interest}

The authors have no financial conflicts of interest.

\section{REFERENCES}

1. Kajitani T. The general rules for the gastric cancer study in surgery and pathology. Part I. Clinical classification. Jpn J Surg 1981;11:127-139.

2. Sano T, Kobori O, Muto T. Lymph node metastasis from early gastric cancer: endoscopic resection of tumour. Br J Surg 1992;79:241-244.

3. Lauwers GY, Riddell RH. Gastric epithelial dysplasia. Gut 1999;45:784790.

4. de Vries AC, Haringsma J, Kuipers EJ. The detection, surveillance and treatment of premalignant gastric lesions related to Helicobacter pylori infection. Helicobacter 2007;12:1-15

5. Chung IK, Lee JH, Lee SH, et al. Therapeutic outcomes in 1000 cases of endoscopic submucosal dissection for early gastric neoplasms: Korean ESD study group multicenter study. Gastrointest Endosc 2009;69:12281235.

6. Nakajima T, Oda I, Gotoda T, et al. Metachronous gastric cancers after endoscopic resection: how effective is annual endoscopic surveillance? Gastric Cancer 2006;9:93-98.

7. Ahn JY, Jung HY. Long-term outcome of extended endoscopic submucosal dissection for early gastric cancer with differentiated histology. Clin Endosc 2013;46:463-466.

8. Choi CW, Kang DH, Kim HW, Park SB, Kim S, Cho M. Endoscopic submucosal dissection as a treatment for gastric adenomatous polyps: predictive factors for early gastric cancer. Scand J Gastroenterol 2012;47:1218-1225

9. Gotoda T. A large endoscopic resection by endoscopic submucosal dissection procedure for early gastric cancer. Clin Gastroenterol Hepatol 2005;3(7 Suppl 1):S71-S73.

10. Kim YY, Jeon SW, Kim J, et al. Endoscopic submucosal dissection for early gastric cancer with undifferentiated histology: could we extend the criteria beyond? Surg Endosc 2013;27:4656-4662.

11. Isomoto H, Shikuwa S, Yamaguchi N, et al. Endoscopic submucosal dissection for early gastric cancer: a large-scale feasibility study. Gut 2009;58:331-336. 
12. Yoo JH, Shin SJ, Lee KM, et al. How can we predict the presence of missed synchronous lesions after endoscopic submucosal dissection for early gastric cancers or gastric adenomas? J Clin Gastroenterol 2013;47:e17-e22.

13. Nitta T, Egashira Y, Akutagawa H, et al. Study of clinicopathological factors associated with the occurrence of synchronous multiple gastric carcinomas. Gastric Cancer 2009;12:23-30.

14. Lee HL, Eun CS, Lee OY, et al. When do we miss synchronous gastric neoplasms with endoscopy? Gastrointest Endosc 2010;71:1159-1165.

15. Japanese Gastric Cancer Association. Japanese classification of gastric carcinoma - 2nd English edition. Gastric Cancer 1998;1:10-24.

16. The Paris endoscopic classification of superficial neoplastic lesions: esophagus, stomach, and colon: November 30 to December 1, 2002. Gastrointest Endosc 2003;58(6 Suppl):S3-S43.

17. Moertel CG, Bargen JA, Soule EH. Multiple gastric cancers; review of the literature and study of 42 cases. Gastroenterology 1957;32:1095-1103.

18. Schlemper RJ, Riddell RH, Kato Y, et al. The Vienna classification of gastrointestinal epithelial neoplasia. Gut 2000;47:251-255.

19. Japanese Gastric Cancer Association. Japanese gastric cancer treatment guidelines 2010 (ver. 3). Gastric Cancer 2011;14:113-123.

20. Hosokawa O, Kaizaki Y, Watanabe K, et al. Endoscopic surveillance for gastric remnant cancer after early cancer surgery. Endoscopy 2002;34:469-473

21. Park CH, Lee H, Kim DW, et al. Clinical safety of endoscopic submucosal dissection compared with surgery in elderly patients with early gastric cancer: a propensity-matched analysis. Gastrointest Endosc 2014;80:599-609.

22. Arima N, Adachi K, Katsube T, et al. Predictive factors for metachronous recurrence of early gastric cancer after endoscopic treatment. J Clin Gastroenterol 1999;29:44-47.

23. Nasu J, Doi T, Endo H, Nishina T, Hirasaki S, Hyodo I. Characteristics of metachronous multiple early gastric cancers after endoscopic mucosal resection. Endoscopy 2005;37:990-993.

24. Han JS, Jang JS, Choi SR, et al. A study of metachronous cancer after endoscopic resection of early gastric cancer. Scand J Gastroenterol 2011;46:1099-1104

25. Goddard AF, Badreldin R, Pritchard DM, Walker MM, Warren B; British Society of Gastroenterology. The management of gastric polyps. Gut 2010;59:1270-1276

26. Kato M, Nishida T, Yamamoto K, et al. Scheduled endoscopic surveillance controls secondary cancer after curative endoscopic resection for early gastric cancer: a multicentre retrospective cohort study by Osaka university ESD study group. Gut 2013;62:1425-1432.

27. Ha TK, An JY, Youn HG, et al. Missed lesions in synchronous multiple gastric cancer. ANZ J Surg 2010;80:276-279.
28. Gong EJ, Lee JH, Jung K, et al. Characteristics of missed simultaneous gastric lesions based on double-check analysis of the endoscopic image. Clin Endosc 2017;50:261-269.

29. Kobayashi M, Narisawa R, Sato Y, Takeuchi M, Aoyagi Y. Self-limiting risk of metachronous gastric cancers after endoscopic resection. Dig Endosc 2010;22:169-173.

30. Hahn KY, Park JC, Kim EH, et al. Incidence and impact of scheduled endoscopic surveillance on recurrence after curative endoscopic resection for early gastric cancer. Gastrointest Endosc 2016;84:628-638.e1.

31. Choi IJ. Endoscopic gastric cancer screening and surveillance in highrisk groups. Clin Endosc 2014;47:497-503.

32. Lee $\mathrm{H}$, Yun $\mathrm{WK}$, Min BH, et al. A feasibility study on the expanded indication for endoscopic submucosal dissection of early gastric cancer. Surg Endosc 2011;25:1985-1993.

33. Cahill RJ, Kilgallen C, Beattie S, Hamilton H, O'Morain C. Gastric epithelial cell kinetics in the progression from normal mucosa to gastric carcinoma. Gut 1996;38:177-181.

34. Esaki Y, Hirokawa K, Yamashiro M. Multiple gastric cancers in the aged with special reference to intramucosal cancers. Cancer 1987;59:560-565.

35. Kato M, Asaka M, Ono S, et al. Eradication of Helicobacter pylori for primary gastric cancer and secondary gastric cancer after endoscopic mucosal resection. J Gastroenterol 2007;42 Suppl 17:16-20.

36. Seo JH, Park JC, Kim YJ, Shin SK, Lee YC, Lee SK. Undifferentiated histology after endoscopic resection may predict synchronous and metachronous occurrence of early gastric cancer. Digestion 2010;81:35-42.

37. Fukase K, Kato M, Kikuchi S, et al. Effect of eradication of Helicobacter pylori on incidence of metachronous gastric carcinoma after endoscopic resection of early gastric cancer: an open-label, randomised controlled trial. Lancet 2008;372:392-397.

38. Correa P. Human gastric carcinogenesis: a multistep and multifactorial process--first American cancer society award lecture on cancer epidemiology and prevention. Cancer Res 1992;52:6735-6740.

39. Chon I, Choi C, Shin CM, Park YS, Kim N, Lee DH. Effect of Helicobacter pylori eradication on subsequent dysplasia development after endoscopic resection of gastric dysplasia. Korean J Gastroenterol 2013;61:307-312.

40. Maehata Y, Nakamura S, Fujisawa K, et al. Long-term effect of Helicobacter pylori eradication on the development of metachronous gastric cancer after endoscopic resection of early gastric cancer. Gastrointest Endosc 2012;75:39-46.

41. Choi J, Kim SG, Yoon H, et al. Eradication of Helicobacter pylori after endoscopic resection of gastric tumors does not reduce incidence of metachronous gastric carcinoma. Clin Gastroenterol Hepatol 2014;12:793-800.e1. 